\title{
Interactions between resin-based temporary materials and immediate dentin sealing
}

Carlos Junio Ribeiro da Silva, Izabela Caroline Santana Gonçalves, Maria Paula Jacobucci Botelho, Ricardo Danil Guiraldo, Murilo Baena Lopes and Alcides Gonini Júnior

*Correspondence: alcides.gonini@gmail.com University of North Parana, CEP Rua Marselha, 183, Londrina, PR 86041-100, Brazil

\begin{abstract}
Bonded indirect restorations require two appointments: one for provisional treatment and one for luting with resin cement and dentin bonding agents (DBA). The DBA layer may be accomplished during a delayed dentin sealing (DDS) step following the provisional phase or an immediate dentin sealing (IDS) step after tooth preparation and during final luting procedures. The purpose of this study was to compare the effect of resin-based provisional material (RBPM) on the tensile bond strength to human dentin developed using DDS and IDS procedures. Flat dentin surfaces were prepared on 48 molars for microtensile testing. The specimens were restored using a 3-step etchand-rinse DBA and composite resin (CR). A set of control specimens (G1) was directly restored using DBA and $C R$, while the remaining samples were treated using a provisional restoration procedure for 2 weeks: DDS + acrylic resin (AR) + calcium hydroxide cement (CHC) (group G2), DDS + AR + eugenol-free cement (G3), DDS + RBPM (G4), IDS + glycerin + RBPM (G5), or IDS + RBPM (G6). After storage of the final restoration in water for $24 \mathrm{~h}$, the specimens were serially sectioned to obtain bonded sticks $0.8 \mathrm{~mm}^{2}$ in area. The tensile strength was tested at a crosshead speed of $0.5 \mathrm{~mm} / \mathrm{min}$. The results were analyzed using ANOVA and Tukey's post hoc tests $(a=0.05)$. The mean (standarddeviation) bond strengths for groups G1-G6 were 42.18 ( \pm 2.63$)$; 40.14 ( \pm 3.46$) ; 37.77$ $( \pm 0.93) ; 37.16( \pm 2.61) ; 34.11( \pm 1.08)$ and $23.79( \pm 0.49) \mathrm{MPa}$. The mean bond strength of group $\mathrm{G} 6$ was significantly lower ( $p<0.05$ ), suggesting that adhesion to dentin is influenced by use of RBPM with IDS prior to placement of a definitive restoration.
\end{abstract}

Keywords: Temporary dental restorations, Composites, Interfaces

\section{Background}

Bonded indirect restorations are laboratory fabricated and requires at least two appointments: one for provisionalization and one for luting. In the first appointment, an impression is immediately taken after tooth preparation, followed by a provisional treatment, which traditionally consists of luting a temporary restoration. After the indirect restoration fabrication, the temporary restoration is removed and an adhesive system is applied to the tooth, after which a resin luting agent is used for the adhesive luting procedure [1].

According to this technique, dentin hybridization is performed following the provisional phase and just before the indirect restoration luting procedure, known as delayed

(c) 2016 Ribeiro da Silva et al. This article is distributed under the terms of the Creative Commons Attribution 4.0 International License (http://creativecommons.org/licenses/by/4.0/), which permits unrestricted use, distribution, and reproduction in any medium, provided you give appropriate credit to the original author(s) and the source, provide a link to the Creative Commons license, and indicate if changes were made. 
dentin sealing. Residual temporary cement may remain on the tooth surface even after mechanical cleaning, and some cement ingredients probably penetrate the tooth surface, altering characteristics such as contact angle and dentin permeability [2]. In this way, the definitive restoration is generally not bonded to freshly-prepared dentin but rather to dentin contaminated, that may result in hybridization failure and reduced bond strength [3].

In order to avoid dentin contamination and the resulting problems, the dual bonding or immediate dentin sealing technique has been proposed $[4,5]$. In this procedure a dentin bonding agent is applied to the fresh cut dentin prior to the placement of the provisional restoration. Immediate dentin sealing requires hybridization of the exposed dentin surface immediately after tooth preparation and during final luting procedures $[6,7]$. The technique prevents the bacterial invasion and dentin sensitivity during the provisional phase, and it is concerned with increased bond strength [4]. Another advantage is that the thickness of dentin bonding agent is considered before tooth preparation impression [8]. The technique could be used with a 3-step etch-and-rinse dentin bonding agent, leading to increased microtensile bond strength compared to delayed dentin sealing. General protocol suggests the use of two step total-etch systems and two-steps self-etch systems as well [3].

Recently, temporary filling materials composed of light-curing composites became an option to traditional cemented temporary restoration [9]. These materials are applied to the dentinal surface without cement and was supposed to be more inert to the dentinal surface prior to bonding [3], but it may decreased the bond strength values affecting adhesive luting. Although, some investigators have suggested that composite materials should not be used on dentin intended to be cemented using resin luting cements and delayed dentin sealing [2], because of possible contamination of hybrid layer. Other authors have examined the bonding potential of sealed dentin surfaces to resin-based provisional materials and cements during immediate dentin sealing and have recommended that prepared teeth be effectively isolated with a separating medium before provisional treatment [7]. There are no data or studies available regarding the dentin bond strength and SEM analysis of immediate sealed dentin with resin-based provisional materials.

The purpose of this investigation was to compare the effect of resin-based temporary materials on the tensile bond strength of bonds to human dentin and definite cement following treatment using the delayed dentin sealing (DDS) or immediate dentin sealing (IDS) procedures.

\section{Methods}

A total of 48 freshly-extracted sound human molars were used in this study. Prior to use, the teeth were stored in $0.5 \%$ chloramine $\mathrm{T}$ solution for up to 7 days and subsequently in distilled water at $4{ }^{\circ} \mathrm{C}$ for a maximum of 6 months.

The teeth were ground in a polishing machine using 180-grit silicon carbide paper to remove the occlusal surfaces and expose flat coronal dentin. The surfaces were evaluated for the presence of remaining enamel, which was removed by additional trimming, and wet polished with 200, 400, and 600-grit silicon carbide paper. 
After flattening, the teeth were randomly assigned to 6 experimental groups $(n=8)$ according to the dentin pretreatment and provisional restorative technique: group 1 (G1/control), freshly ground dentin; groups 2, 3, and 4 (G2, G3, and G4), dentin contaminated with provisional restoration material and sealed dentin (DDS); and groups 5 and 6 (G5 and G6), sealed dentin and sealed dentin contaminated (IDS) with provisional restoration material. The specific treatment parameters are listed in Fig. 1 and the materials used in this study are shown in Table 1.

In the control specimens (G1) the dentin was sealed immediately after preparation using a 3-step etch-and-rinse adhesive system (Adper ScotchBond Multi-Purpose, $3 \mathrm{M}$ ESPE, St. Paul, MN, USA) and restored using a composite resin (Z350 XT, 3 M ESPE, St. Paul, MN, USA). Hybridization consisted of successive application of the conditioner (acid etchant), primer (adhesion promoter), and bonding agent (adhesive resin), followed

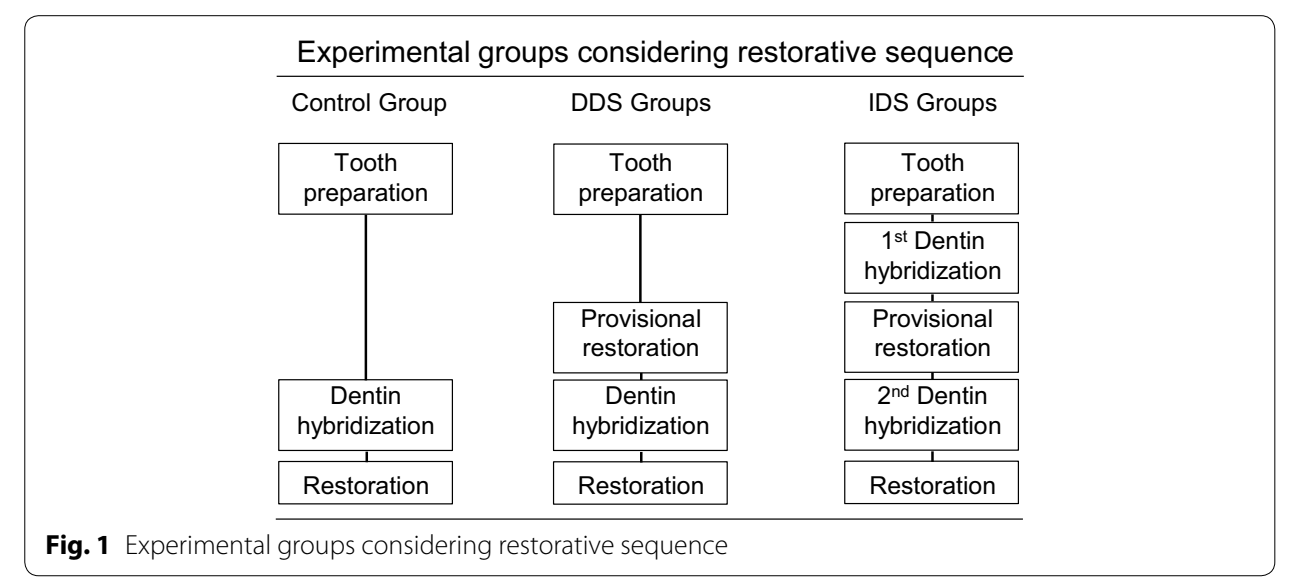

Table 1 Materials used in this study

\begin{tabular}{|c|c|c|c|}
\hline Materials & Product name & Composition & Manufacturer \\
\hline Calcium hydroxide cement & Dycal & $\begin{array}{l}\text { Base paste: 1,3-butylene gly- } \\
\text { col disalicyate, zinc oxide, } \\
\text { calcium phosphate, calcium } \\
\text { tungstate, iron oxide } \\
\text { pigments. Catalyst paste: } \\
\text { calcium hydroxide, N-ethyl- } \\
\text { o/p-toluene sulfonamide, } \\
\text { zinc oxide, titanium dioxide, } \\
\text { zinc stearate, iron oxide } \\
\text { pigments }\end{array}$ & Dentsply, York, USA \\
\hline Eugenol-free cement & Temp bond NE & $\begin{array}{l}\text { Base paste: mineral oil, zinc } \\
\text { oxide, cornstarch. Catalyst } \\
\text { paste: resin, ortho-ethoxy } \\
\text { benzoic acid, carnauba wax, } \\
\text { octanoic acid }\end{array}$ & Kerr, orange, USA \\
\hline $\begin{array}{l}\text { Resin-based provisional } \\
\text { material }\end{array}$ & Clip F & $\begin{array}{l}\text { UDMA, DDMA, polymers, } \\
\text { fluoride }\end{array}$ & Voco, cuxhaven, GER \\
\hline Dentin bonding agent & $\begin{array}{l}\text { Adper ScotchBond multi- } \\
\text { purpose }\end{array}$ & $\begin{array}{l}\text { Primer: HEMA, polyalkenoic } \\
\text { acid. Bond: Bis-GMA, HEMA, } \\
\text { amines }\end{array}$ & 3 M ESPE, St Paul, USA \\
\hline
\end{tabular}

UDMA urethanedimethacrylate, DDMA dodecanidiol dimethacrylate (DDMA), HEMA hydroxiethylmethacrylate, Bis-GMA bisphenol-glycidyl methacrylate 
by light-induced polymerization [10]. The composite restorations were prepared as successive $2.0 \mathrm{~mm}$-thick layers of resin. All materials were used according to the manufacturer's instructions.

Groups G2 and G3 were first restored using an acrylic resin provisional restoration fixed respectively with a calcium hydroxide (Dycal, Dentsply, York, USA) or zinc oxide non-eugenol based (Temp Bond NE, Kerr, Orange, USA) temporary cement, while G4 was first restored using a methacrylate-based temporary restorative material (Clip F, Voco, Cuxhaven, GER). The samples were immersed in $0.9 \%$ saline solution for 2 weeks [11], after which all temporary restorations and any residual cement were removed from the dentinal surface using a curette. The surface was cleaned using non-fluoridated pumice flour for $10 \mathrm{~s}$, then sealed and restored in a manner similar to the control group.

In groups G5 and G6, the dentin was first sealed immediately after preparation and then restored using the methacrylate-based temporary restorative material. In group G5 the sealed surfaces were isolated using glycerin gel before application of the temporary restoration, while in group G6 the temporary restorative material was applied directly to the sealed dentinal surface. The remaining treatment procedures were similar to those of the DDS groups.

After final restoration, all specimens were stored in distilled water at $37^{\circ} \mathrm{C}$ for $24 \mathrm{~h}$, then sectioned in the mesiodistal and buccolingual directions perpendicular to the bonded interfaces using an Isomet 1000 machine (Buhler, Lake Bluff, IL, USA), yielding rectangular samples with a calculated cross-sectional area of $0.8 \mathrm{~mm}^{2}$. The samples were secured in a microtensile testing fixture (Odeme Biotechnology, Joaçaba, SC, Brazil) using cyanoacrylate-based adhesive (Super Bonder Gel, Loctite, Itapevi, SP, Brazil) and tested in a universal testing machine (EMIC DL 2000, São José dos Pinhais, PR, Brazil) at a crosshead speed of $0.5 \mathrm{~mm} / \mathrm{min}$. The rationale behind microtensile bond strength methodology [12] is that the higher the actual bonding capacity of an adhesive, the better it will withstand such stresses and the longer the restoration would survive clinically [10].

The bond strength values (MPa) were analyzed using one-way analysis of variance and Tukey's test at $5 \%$ significance level. Fragments of the fractured specimens were observed using an optical microscope at $40 \times$ magnification and the modes of fracture were classified as adhesive, cohesive (dentin or composite substrate), or mixed. Scanning electron micrographs (SEM) were obtained of representative surfaces from samples in groups G4, G5, and G6.

\section{Results and discussion}

Considering indirect bonded restorations, success is highly dependent on the adhesive procedure, particularly in terms of dentin preparation [6,7]. A primary requirement for optimum bonding is a contaminant-free substrate, such as that obtained at the time of preparation when the dentin is freshly cut and clean $[3,13]$.

The traditional DDS procedure is performed when the dentin bonding agent is applied, after the temporary restorative period and just prior to permanent cementation of the restoration. This procedure may result in lower bond strength to the tooth structure due to residual surface contamination from the temporary restoration [14]. 
Despite this potential, there was no significant reduction in tensile bond strength between the DDS and control groups (Table 2), even when a resin-based temporary material was used (G4).

The bonding of final restorations to teeth using resin luting cement may be adversely affected by temporary cement of any type [15]. This effect is most serious when zinc oxide-eugenol based luting agent is used for provisional cementation because eugenol inhibits polymerization of dentin bonding agents and luting resins [16]. However, even eugenol-containing provisional cements may be used prior to resin cementation if the dentin is aggressively cleaned with non-fluoridated pumice before dentin bonding [3]. In order to avoid convolution of the results due to the effects of eugenol-based provisional cement, only non-eugenol based materials were employed in this study.

It is questionable whether cleaning the dentinal surface using pumice alone is sufficient to remove temporary material before adhesive luting [3], as well as is etching with $37 \%$ phosphoric acid [16]. In this study the temporary material was mechanically removed using a curette [9] before cleaning with non-fluoridated pumice flour and conditioning with acid. The shear bond strength values following this cleaning were similar to those of the control group, in contrast to previous reports [3, 14, 17]. It is possible that the mechanical cleaning efforts are responsible for the improved bonding in general [18].

Even after assumed thorough removal of the temporary material, distinguished areas could be observed along the dentin surface in scanning electron micrographs, particularly in group G4, suggesting the presence of residual temporary material (Fig. 2). However, even if penetration of ingredients into the tooth surface or ion leakage into deeper zones of the superficial strata of the dentin occurred [3], this was not sufficient to affect the adhesion of the final restoration, different from previous results $[2,19]$.

Table 2 Mean microtensile bond strength values (MPa) and standard deviation (SD)

\begin{tabular}{|c|c|c|c|c|c|c|}
\hline \multirow[b]{2}{*}{$n=8$} & \multirow{2}{*}{$\begin{array}{l}\text { Control group } \\
\text { G1 }\end{array}$} & \multicolumn{3}{|c|}{ DDS groups } & \multicolumn{2}{|c|}{ IDS groups } \\
\hline & & G2 & G3 & G4 & G5 & G6 \\
\hline Mean & $42.18^{a}$ & $40.14^{a}$ & $37.77^{a}$ & $37.16^{a}$ & $34.11^{a}$ & $23.79^{b}$ \\
\hline SD & 7.4 & 9.8 & 2.6 & 7.4 & 3.0 & 1.4 \\
\hline
\end{tabular}

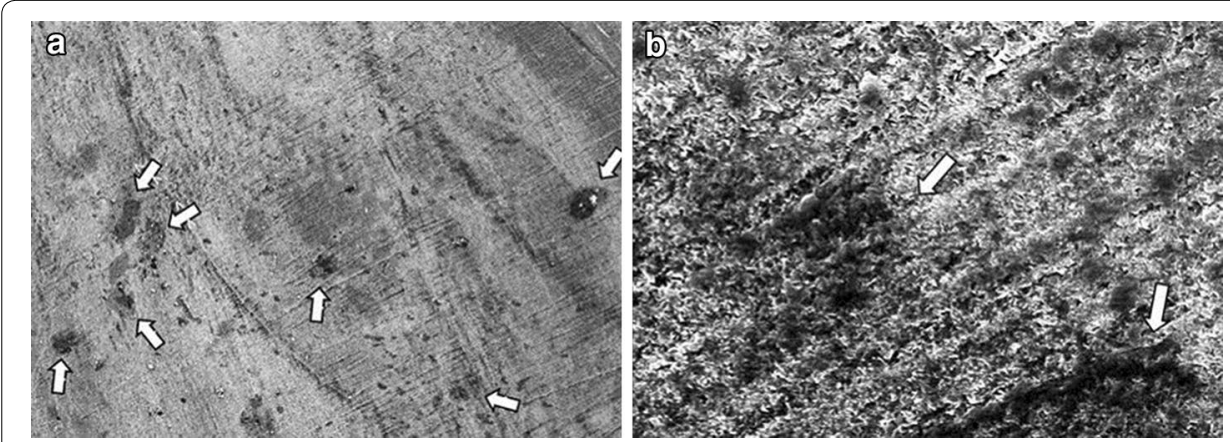

Fig. 2 SEM view of supposed contaminated areas of dentin surface in G4 (arrows), considering original magnification $35 \times(\mathbf{a})$ and $1000 \times(\mathbf{b})$ 
The distribution of failure modes in the DDS groups is described in Table 3. Mixed fractures were the most prevalent fracture mode in groups G2, G3, and G4. Group G4 experienced thee times more adhesive failures than group G2 and nine times more than group G3, suggesting that methacrylate-based materials have greater potential to interfere with resin-coated dentin surfaces than provisional cements.

Within the limits of this study, the DDS procedure provided the optimum conditions for bonding even on contaminated dentin surfaces. IDS was intended to provide advantages such as protection from infiltration and bacterial leakage during the provisional restoration stage, reduction of potential risk for postcementation sensitivity, minimization of anesthesia required during cementation of the definitive restoration, and improved bond strength to the tooth structure [6], as well as addressing the primary problem of reduced shear bond strength associated with provisional treatment. A key element in IDS is the development of an effective bond between the existing resin coating and the new luting composite resin [7], considering that bond strength could start to decreased after 7 days after IDS procedure [20].

The effectiveness of this bond could be compromised because sealed dentin surfaces have the potential to strongly attach to resin-based provisional materials, suggesting that this type of provisional material should be avoided [6] due to subsequent difficulties in removing resin-based provisional restorations. This difficulty may be avoided by isolating sealed dentin using a separating medium just before provisional treatment $[6$, 7]. This was confirmed in the present study, in which significant reductions in bond tensile strength were observed when the IDS groups (G5 and G6) were compared to each other and to the control group (Table 1). Water-soluble glycerin was used as a separating medium instead of the petroleum jelly $[3,21]$ because oily additives are more difficult to remove from sealed dentin [21]. As a result, the hybrid layer was preserved after mechanical removal of the resin-based provisional material in G5 (Fig. 3).

Methacrylate-based temporary material obviously adheres well to sealed dentin and may be removed only using a scaler [9,21]. Even so, mechanical removal did not appear to be effective, based on a comparison of the bond strengths of groups G5 and G6 (Table 2). The strong adhesive interaction may have removed part of the hybrid

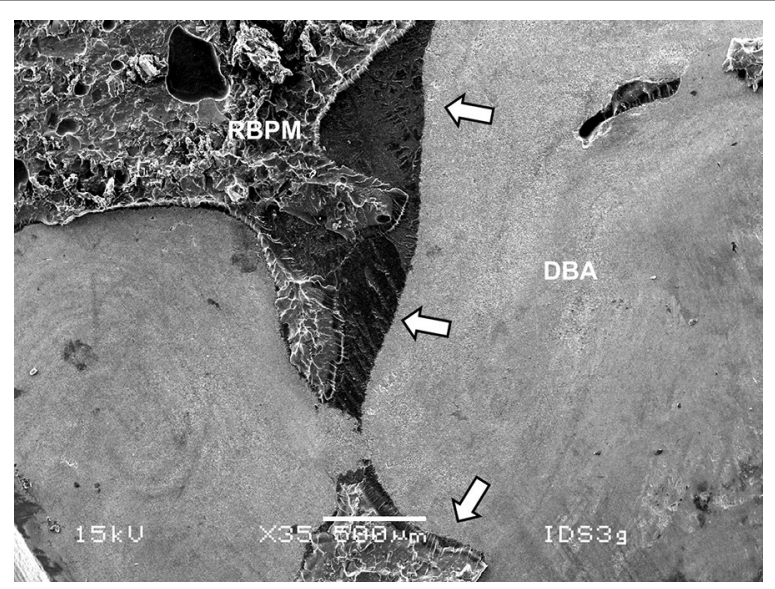

Fig. 3 SEM of preserved dental bonding agent (DBA) layer after partial mechanical removal of resin-based provisional material (RBPM) in Group 5. Topography image at the edge of RBPM and DBA (arrows) 
layer, resulting in lower bond strength even after a second application of bonding agent (Figs. 4, 5). These findings are supported by a higher rate of adhesive failure in G6 compared to G5 (Table 3) indicating that the hybrid layer was the weakest link.

Group G6 exhibited significantly lower bond strength values (Table 2). Mixed fractures were the most common in all groups except G6, in which adhesive fractures were most prevalent (Table 3).

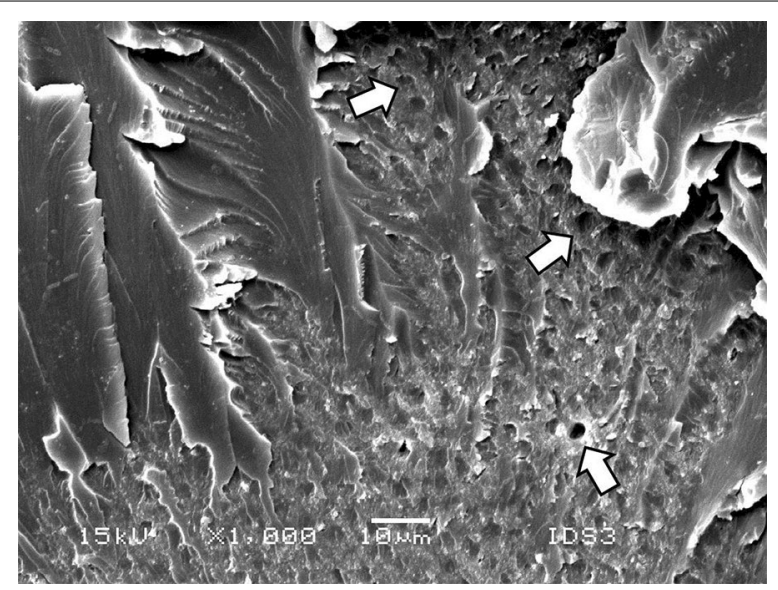

Fig. 4 SEM of resin-based provisional material (RBPM) bonded to dental bonding agent in Group 6. Exposed dentinal tubules after partial mechanical removal of RBPM (arrows)

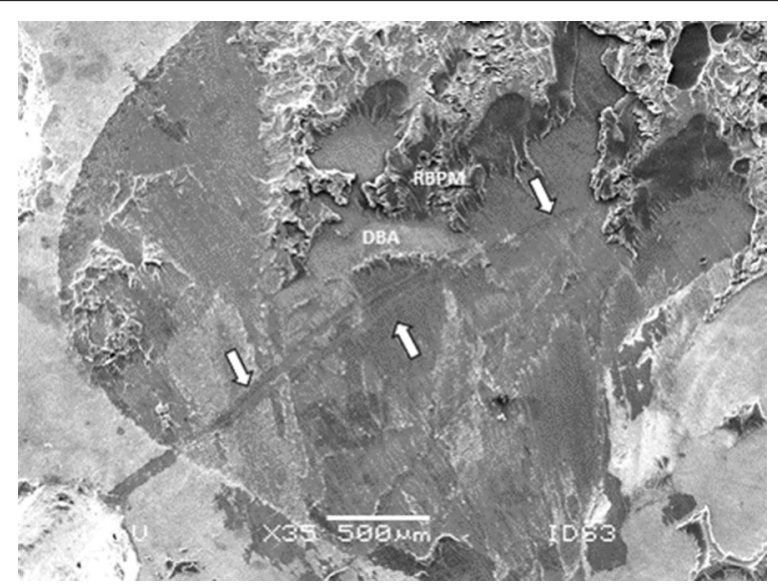

Fig. 5 SEM view of sealed dentinal surface in Group 6 specimen (original magnification 35X). The arrows indicate marks left on dental bonding agent (DBA) after partial resin-based provisional material (RBPM) mechanical removal

Table 3 Distribution of failures modes (\%) as observed by optical microscopy

\begin{tabular}{lccccccc}
\hline Groups & Control group & \multicolumn{2}{c}{ DDS groups } & & \multicolumn{2}{c}{ IDS groups } \\
& G1 & G2 & G3 & G4 & & G5 & G6 \\
\hline Adhesive & 12.5 & 6.3 & 2.1 & 18.8 & & 22.9 & 54.2 \\
Cohesive in resin & 6.3 & 0 & 8.3 & 6.3 & 0 & 0 \\
Cohesive in dentin & 12.5 & 33.3 & 31.3 & 22.9 & 16.7 & 8.3 \\
Mixed & 68.7 & 60.4 & 58.3 & 52.0 & & 60.4 & 37.5 \\
\hline
\end{tabular}


There were no data until now, supporting that RBPM could not be applied whit IDS. This study was a quantitative evaluation with the objective of identifying possible interactions between a RBPM and IDS procedure. It could be observed that mechanical removal of RBPR was difficult and not only comparative results demonstrated the substrates interaction. Actually the results demonstrated that tooth preparations must be rigorously isolated in RBPM and IDS association and not necessarily with DDS.

\section{Conclusion}

The bond strength of restorations to human dentin was relatively constant independent of the provisional restorative material used in the DDS procedure, while the use of resinbased temporary material in the IDS procedure has the property to reduce the bond strength unless the provisional bonding layer is isolated using a water-soluble gel.

\section{Authors' contributions}

CJRS and ICSG participated in performing the experiments and writing of the manuscript, MPJB performed the statistical analysis and contributed to the writing of the manuscript, RDG performed the microscopic analysis, MBL and AGJ conceived the study, participating in its design and coordination, helping to drafting the manuscript. All authors read and approved the final manuscript.

\section{Competing interests}

The authors declare that they have no competing interests.

Received: 14 December 2015 Accepted: 8 March 2016

Published online: 15 March 2016

\section{References}

1. Swift EJ Jr. Critical appraisal; immediate dentin sealing for indirect bonded restorations. J Esthet Restor Dent. 2009;21:62-7.

2. Tetsuka N. Influence of temporary cement on dentin permeability. Japan J Conserv Dent. 1993;36:822-8.

3. Paul SJ, Schärer P. Effect of provisional cements on bond strength of various adhesive bonding systems on dentin. J Oral Rehabil. 1997;24:8-14.

4. Pashley EL, Comer RW, Simpson MD, Homer JA, Pashley DH, Caughman WF. Dentin permeability: sealing the dentin in crown preparations. Oper Dent. 1992;17:13-20.

5. Nikaido T, Takada T, Burrow MF, Tagami J. The early bond strength of dual cured resin cement to enamel and dentin. J Jpn Dent Mater. 1992;11:910-5.

6. Magne P. Immediate dentin sealing: a fundamental procedure for indirect bonded restorations. J Esthet Restor Dent. 2005;17:144-55.

7. Magne P, So WS, Cascione D. immediate dentin sealing supports delayed restoration placement. J Prosthet Dent 2007;98:166-74

8. Spohr AM, Borges GA, Platt JA. Thickness of immediate dentin sealing materials and its effect on the fracture load of a reinforced all-ceramic crown. Eur J Dent. 2013;7:474-83.

9. Rocca GT, Krejci I. Bonded indirect restorations for posterior teeth: the luting appointment. Quint Int. 2007:7:543-53.

10. Van Meerbeek B, De Munck J, Yoshida Y, Inoue S, Vargas M, Vijay P, Van Landuyt K, Lambrechts P, Vanherle G. Adhesion to enamel and dentin: current status and future challenges. Oper Dent. 2003;28:215-35.

11. Magne P, Kim TH, Cascione D, Donovan TE. Immediate dentin sealing improved bond strength of indirect restorations. J Prosthet Dent. 2005;94:511-9.

12. Sano H, Shono T, Sonoda H, Takatsu T, Ciucchi B, Carvalho R, Pashley DH. Relationship between surface area for adhesion and tensile bond strength—evaluation of a microtensile bond test. Dent Mat. 1994;10:236-40.

13. Watanabe EK, Yamashita A, Imai M, Suzuki K. Temporary cements remnants as an adhesion inhibiting factor in the interface between resin cements and bovine dentin. Int J Prosthod. 1997;10:440-52.

14. Choi YS, Cho IH. An effect of immediate dentin sealing on the shear bond strength of resin cement to porcelain restoration. J Adv Prosthodont. 2010;2:39-45.

15. Terata R, Nakashima K, Obara M, Kubota M. Characterization of enamel and dentin surfaces after removal of temporary cement. Dent Mat J. 1994;13:148-54.

16. Terata R. Characterization of enamel and dentin surfaces after removal of temporary cement. Dent Mat J. 1993;12:18-28.

17. Erkut S, Küçükesmen HC, Eminkahyagil N, Imirzalioglu P, Karabulut E. Influence of previous provisional cementation on bond strength between two definitive resin-based luting and dentin bonding agents and human dentin. Oper Dent. 2007;32:84-93.

18. Saraç D, Külünk S, Saraç YS, Karakas O. Effect of fluoride-containing desensitizing agents on the bond strength of resin-based cements to dentin. J Appl Oral Sci. 2009;17:495-500. 
19. Leesungbok R, Lee SM, Park SJ, Lee SJ, Lee DY, Im BJ, Ahn SJ. The effect of IDS (immediate dentin sealing) on dentin bond strength under various thermocycling periods. J Adv Prosthodont. 2015;7:224-32.

20. Givens EJ Jr, Neiva G, Yaman P, Dennison JB. Marginal adaptation and color stability of four provisional materials. J Prosthodont. 2008;17:97-101.

21. Bertschinger C, Paul SJ, Lüthy H, Schärer P. Dual application of dentin bonding agents: effect on bond strength. Am J Dent. 1996;9:115-9.

Submit your manuscript to a SpringerOpen ${ }^{\circ}$ journal and benefit from:

- Convenient online submission

- Rigorous peer review

- Immediate publication on acceptance

- Open access: articles freely available online

- High visibility within the field

- Retaining the copyright to your article

Submit your next manuscript at $\boldsymbol{s p r i n g e r o p e n . c o m ~}$ 